\title{
Systematization, distribution, and territories of the caudal cerebral artery on the surface of the brain in nutria (Myocastor coypus) ${ }^{\mathbf{1}}$
}

\author{
Laura V. Goltz ${ }^{2 *}$ (D), Rodrigo C. Azambuja ${ }^{2}$ and Rui Campos ${ }^{3}$
}

\begin{abstract}
Goltz L.V., Azambuja R.C. \& Campos R. 2020. Systematization, distribution and territories of the caudal cerebral artery on the surface of the brain in nutria (Myocastor coypus). Pesquisa Veterinária Brasileira 40(6):484-492. Departamento de Ciências Morfológicas, Instituto de Ciências Básicas da Saúde, Universidade Federal do Rio Grande do Sul, Av. Bento Gonçalves 9090, Bairro Agronomia, Porto Alegre, RS 91540-000, Brazil. E-mail: lauragoltz@gmail.com

The nutria (Myocastor coypus) is a medium-sized, semi-aquatic rodent valued by the skin and meat industry. This study aimed to describe and systematize the caudal cerebral artery on the brain surface in nutria, establishing a standard model and its main variations in this species. The thirty animals used were euthanized according to animal welfare rules. The vessels were filled with latex stained with red pigment and the samples were fixed in formaldehyde. In nutria, the brain was vascularized by the vertebral basilar system. The terminal branches of the basilar artery originated the rostral cerebellar, caudal cerebral, rostral choroidal and middle cerebral arteries, and its terminal branch, the rostral cerebral artery. The terminal branch of the basilar artery projected the caudal cerebral artery, which is usually a single medium-caliber vessel, into the transverse fissure of the brain. The caudal cerebral artery was presented as a single ( $66.7 \%$ of the cases to the right and $76.7 \%$ to the left) and double vessel (33.3\% of the cases to the right and $23.3 \%$ to the left). It originated the rostral mesencephalic artery, the proximal component, and the caudal inter-hemispheric artery. The terminal branches of the rostral and caudal tectal mesencephalic arteries formed a typical anastomotic network. The caudal inter-hemispheric artery emitted central branches, the caudal choroidal artery, hemispherical occipital arteries, rostral tectal mesencephalic branches and distal components, and anastomosed "in osculum" with the terminal branches of the rostral inter-hemispheric artery. The caudal choroidal artery anastomosed with the rostral choroidal artery, where it branched out on the thalamic mass, vascularizing all diencephalic structures and the hippocampus. The caudal cerebral artery and its terminal branches anastomosed with the terminal branches of the rostral and middle cerebral arteries in a restricted region of the caudal pole of the cerebral hemisphere. The vascularization area of the caudal cerebral artery and its central branches in the paleopallial of the piriform lobe is extremely restricted, caudomedially.
\end{abstract}

INDEX TERM: Caudal cerebral artery, brain, nutria, Myocastor coypus, arterial vascularization, anatomy, rodents.

\author{
RESUMO.-[Sistematização, distribuição e territórios \\ da artéria cerebral caudal na superfície do cérebro em \\ Nutria (Myocastor coypus).] A nutria (Myocastor coypus)

\footnotetext{
${ }^{1}$ Received on December 11, 2019.

Accepted for publication on February 4, 2020.

${ }^{2}$ Graduate Program in Veterinary Science (PPGCV), Universidade Federal do Rio Grande do Sul (UFRGS), Av. Bento Gonçalves 9090, Bairro Agronomia, Porto Alegre, RS 91540-000, Brazil.*Corresponding author: lauragoltz@gmail.com

${ }^{3}$ Departamento de Ciências Morfológicas, Instituto de Ciências Básicas da Saúde (ICBS), Universidade Federal do Rio Grande do Sul (UFRGS), Av. Bento Gonçalves 9090, Bairro Agronomia, Porto Alegre, RS 91540-000, Brazil.
}

é um roedor semi-aquático de tamanho mediano, apreciado na indústria de peles e carne. Este trabalho tem por objetivo descrever e sistematizar a artéria cerebral caudal na superfície do cérebro em nutria, estabelecendo um modelo padrão e suas principais variações e territórios nesta espécie. Os trinta animais utilizados foram eutanasiados segundo as regras de bem-estar animal, os vasos foram preenchidos com látex, corado em vermelho e as peças foram fixadas em formoldeído. 0 cérebro foi vascularizado exclusivamente pelo sistema vértebro-basilar. Os ramos terminais da artéria basilar originaram as artérias cerebelar rostral, cerebral 
caudal, corióidea rostral, cerebral média e seu ramo terminal, a artéria cerebral rostral. 0 ramo terminal da artéria basilar lançou a artéria cerebral caudal, um vaso normalmente único, de médio calibre, para o interior da fissura transversa do cérebro. A artéria cerebral caudal foi um vaso único em $66,7 \%$ à direita e em $76,7 \%$ à esquerda e mostrou-se dupla em $33,3 \%$ à direita e em $23,3 \%$ à esquerda. Ela lançou a artéria tectal mesencefálica rostral, componente proximal e a artéria inter-hemisférica caudal. Os ramos terminais das artérias tectais mesencefálicas, rostral e caudal, formavam uma rede anastomótica típica. A artéria inter-hemisférica caudal lançou ramos centrais, a artéria corióidea caudal, as artérias hemisféricas occipitais, os ramos tectais mesencefálicos rostrais, componentes distais e anastomosou-se "em ósculo" com o ramo terminal da artéria inter-hemisférica rostral. A artéria corióidea caudal anastomosava-se com a artéria corióidea rostral, onde ramificavam-se sobre a massa talâmica, vascularizando todas as estruturas do diencéfalo e hipocampo. A artéria cerebral caudal com seus ramos terminais apresenta anastomoses com os ramos terminais das artérias cerebrais rostral e média em uma região restrita do pólo caudal do hemisfério cerebral. A área de vascularização da artéria cerebral caudal com seus ramos centrais no páleo-palio do lobo piriforme é extremamente restrita, caudo-medialmente ao mesmo.

TERMOS DE INDEXAÇÃO: Artéria cerebral caudal, cérebro, nutria, Myocastor coypus, vascularização arterial, anatomia, roedores.

\section{INTRODUCTION}

Research on the central nervous system functions has been intensified in recent years, bringing the need to increase knowledge on cerebral vascularization. The present study was conducted with this intention.

The first studies on brain irrigation (Tandler 1898, De Vriese 1905) brought important considerations on the phylogenesis and ontogenesis of brain arterial models.

This study discusses the systematization, description, ramifications, and territory of the caudal cerebral artery on the brain surface in nutria (Myocastor coypus), a mediumsized, semi-aquatic rodent appreciated by the fur and meat industry, which lives in wetlands, rivers and lakes, where it digs burrows along the banks and feeds on grass, roots and aquatic plants (Baroffio et al. 1979).

Studies addressing brain irrigation have been carried out with several species such as dogs (Alcântara 1992), wild boars (Oliveira 2004), pampas foxes (Depedrini \& Campos 2003), chickens (Gallus gallus) (Campos 1987), domestic pigs (Ferreira 1998), and opossums (Lindemann 1994). In rodents, there are reports in chinchillas (Jablonski \& Brudnicki 1984, Roskosz et al. 1988, Gielecki et al. 1996, Araújo et al. 2004, Araújo \& Campos 2005, Araújo \& Campos 2007), capybaras (Reckziegel et al. 2001, 2004a, 2004b), guinea pigs (Cavia porcellus) (Bugge 1971, 1974), muskrats (Ondatra zibethica) (Jablonski \& Brudnicki 1984), guinea pigs (Cavia cobaya), rats (Mus rattus) (Tandler 1898, De Vriese 1905), mice (Mus muscullus and Rattus norvegicus) (Lazorthes et al. 1976, Scremin 1995), guinea pigs (Majewska-Michalska 1995, 1997), gerbils (Meriones unguiculatus) (Kuchinka et al. 2008), Cairo spiny mice (Acomys cahirinus, Desmarest) (Szczurkowski et al. 2007), and nutrias (Azambuja et al. 2018, Goltz 2017).
Due to the lack of information on this species, both in the classic literature and in specialized articles, our results will be compared with those reported by other authors who have discussed brain vascularization in rodents.

This study aimed to describe and systematize the caudal cerebral artery on the surface of the brain in nutria to understand the phylogenetic development of this vessel, establishing a standard model and its main variations and territories in this species.

\section{MATERIALS AND METHODS}

Thirty brains of adult nutrias (Myocastor coypus), 15 males and 15 females, from a commercial breeding farm, certified by the Brazilian Institute of the Environment and Renewable Natural Resources (IBAMA), located in the municipality of Caxias do Sul, state of Rio Grande do Sul, Brazil, were used to in this study. The project was approved by the Committee on Animal Research and Ethics of the Federal University of Rio Grande do Sul (CEUA-UFRGS) under protocol no. 29415. The specimens provided for the experiments were animals that would be discarded by the breeder.

The animals were physically restrained and received a 10,000IU dose of heparin (Hepamax-s; Blausiegel Indústria e Comércio Ltda, Cotia/SP, Brazil), intraperitoneally. After $30 \mathrm{~min}$, the animals were sedated with an association of the following pre-anesthetic medications: acepromazine (Acepran 1\%; Vetnil, Louveira/SP, Brazil) $0.5 \mathrm{mg} / \mathrm{kg}$ and pethidine hydrochloride (Dolosal; União Química, São Paulo/SP, Brazil) $20 \mathrm{mg} / \mathrm{kg}$, intramuscularly. After sedation, they were euthanized using sodium thiopental (Thiopentax 2.5\%; Cristalia, Itapira/SP, Brazil) at a dose of $120 \mathrm{mg} / \mathrm{kg}$ and lidocaine (Dorfin 1\%; Hertape Calier, Juatuba/MG, Brazil), at 1\% concentration, intraperitoneally.

After confirmation of death, the thoracic cavity was opened ventrally. The thoracic aorta was clamped close to the diaphragm, the cardiac apex was sectioned, and the aortic arch was cannulated through the left ventricle. The internal thoracic artery was clamped close to the xiphoid process. The arterial system was washed with $150 \mathrm{ml}$ per animal of refrigerated $0.9 \%$ saline solution (Sodium Chloride 0.9\%; Fresenius Kabi Brasil, Barueri/SP, Brazil), and filled with latex (Latex Cola 603; Bertoncini, São Paulo/SP, Brazil) stained with red pigment (Suvinil Corante; Suvinil BASF, São Bernardo do Campo/SP, Brazil). The animals were immersed in running water for approximately 1 hour allow to polymerization of the latex. The head skin was removed and a bone window was opened in the cranial vault. The samples were then immersed in $20 \%$ formaldehyde for seven days. After this period, the encephala were removed along with a segment of the cervical spinal cord for dissection and observation of the cerebral arteries.

The material was analyzed under magnifying lens (LTS lamp, 5X magnification, and Stemi SV8 microscope - Zeiss, Goettingen, Germany) and, to illustrate the results, schematic drawings of the cerebral arteries on the surface of the brain were made in ventral, dorsal, right and left lateral, right and left medial, and dorsal brainstem views for all samples. Photographic records of the preparations were made for documentation.

The vessels were named according to Nomina Anatomica Veterinaria (2017), with some names were added, at our discretion, based on the blood supply territories of other animal species found in literature. Percentage calculations were applied to statistically analyze the results. 


\section{RESULTS}

The internal carotid artery, right and left, in nutria (Myocastor coypus) was atrophied in both antimeres in all cases. Its terminal branch was found at the base of the skull before penetrating the foramen lacerum, not cooperating to the arterial vascularization of the brain.

The brain was vascularized exclusively by the vertebrobasilar system. The vertebral artery was a collateral branch of the subclavian artery, ascending the neck through the transverse canal of the cervical vertebrae. When it reached the atlantal fossa, it crossed the alar and lateral vertebral foramina of the tlas, reaching the interior of the vertebral canal. Its terminal branch was anastomosed with its contralateral counterpart, on the ventral surface of the medulla, forming a basilar artery of large caliber when penetrating through the foramen magnum.

The basilar artery, a large caliber rectilinear vessel, when ventrally traversing the base of the rhombencephalon, emitted pairs of caudal, medium and trigeminal cerebellar arteries dividing into its terminal branches, which diverged laterorostrally at an approximate angle of $90^{\circ}$.

The terminal branches of the basilar artery originated, in sequence, the rostral cerebellar, caudal cerebral, rostral choroid, middle cerebral arteries, and its terminal branch, the rostral cerebral artery (Fig.1).

The rostral cerebellar artery originated from the terminal branch of the basilar artery, penetrated the transverse fissure of the brain, vascularized a large part of the cerebellum, and emitted the caudal tectal mesencephalic branch to the caudal surface of the caudal colliculi.

The terminal branch of the basilar artery projected the caudal cerebral artery into the transverse fissure of the brain, along with the apparent origin of the oculomotor nerve (III pair of cranial nerve).

The caudal cerebral artery was a regular, single, mediumcaliber vessel. It projected lateral-dorsally into the transverse fissure of the brain, bypassing the cerebral peduncle. The rostral tectal mesencephalic artery was projected caudaldorsally, and vascularized most of the mesencephalic tectum, except the caudal surface of the caudal colliculi, which was vascularized by the caudal tectal artery, a branch of the rostral cerebellar artery. This network also received ramifications from the two rostral mesencephalic tissue vessels, a distal component that was emitted from the inter-hemispheric artery and the caudal choroidal artery at the height of the lateral surface of the rostral colliculi (Fig.2).

The next branch of the caudal cerebral artery was the caudal inter-hemispheric artery, which emitted two to three central branches to the medial surface of the piriform lobe, caudal part. Then it emitted a well-developed caudal choroidal artery, which, before bypassing the lateral geniculate body, anastomosed with the rostral choroidal artery, where both branched out on the thalamic mass, vascularizing all the structures of the diencephalon (lateral geniculate body, pineal gland, medullary streak, and third ventricle choroid plexus), as well as the entire hippocampus. Next, the caudal inter-hemispheric artery emitted two to three occipital hemispheric arteries to the medial part (tentorialpart) of the cerebral hemisphere, small vessels that reached the occipital pole (caudal) of the cerebral hemisphere. The caudal interhemispheric artery then became a thin vessel that, bypassing the splenium of the corpus callosum, anastomosed "in osculum" with the termination of the rostral inter-hemispheric artery. Before the cerebral hemisphere, the caudal inter-hemispheric artery emitted, mid-caudally, two rostral tectal mesencephalic branches, distal components, which were incorporated into the network of the mesencephalic tectum (Fig.3).

The caudal cerebral artery was presented as a single vessel $(66.7 \%$ of the cases to the right and $76.7 \%$ to the left) and double vessel (33.3\% of the cases to the right and $23.3 \%$ to the left). In the samples where the caudal cerebral artery was presented as a double vessel, the first component emitted from the terminal branch of the basilar artery was the rostral tectal mesencephalic artery, its proximal component. Where the caudal cerebral artery was presented as a single vessel, the rostral tectal mesencephalic artery was its first collateral branch. It also originated at the base of the brain before penetrating its transverse fissure.

The rostral tectal mesencephalic artery, a proximal component, appeared as the first collateral branch of the caudal cerebral artery in 66.7 and $76.7 \%$ of the cases to the right and the left, respectively, and was presented as the first collateral branch of the terminal branch of the basilar

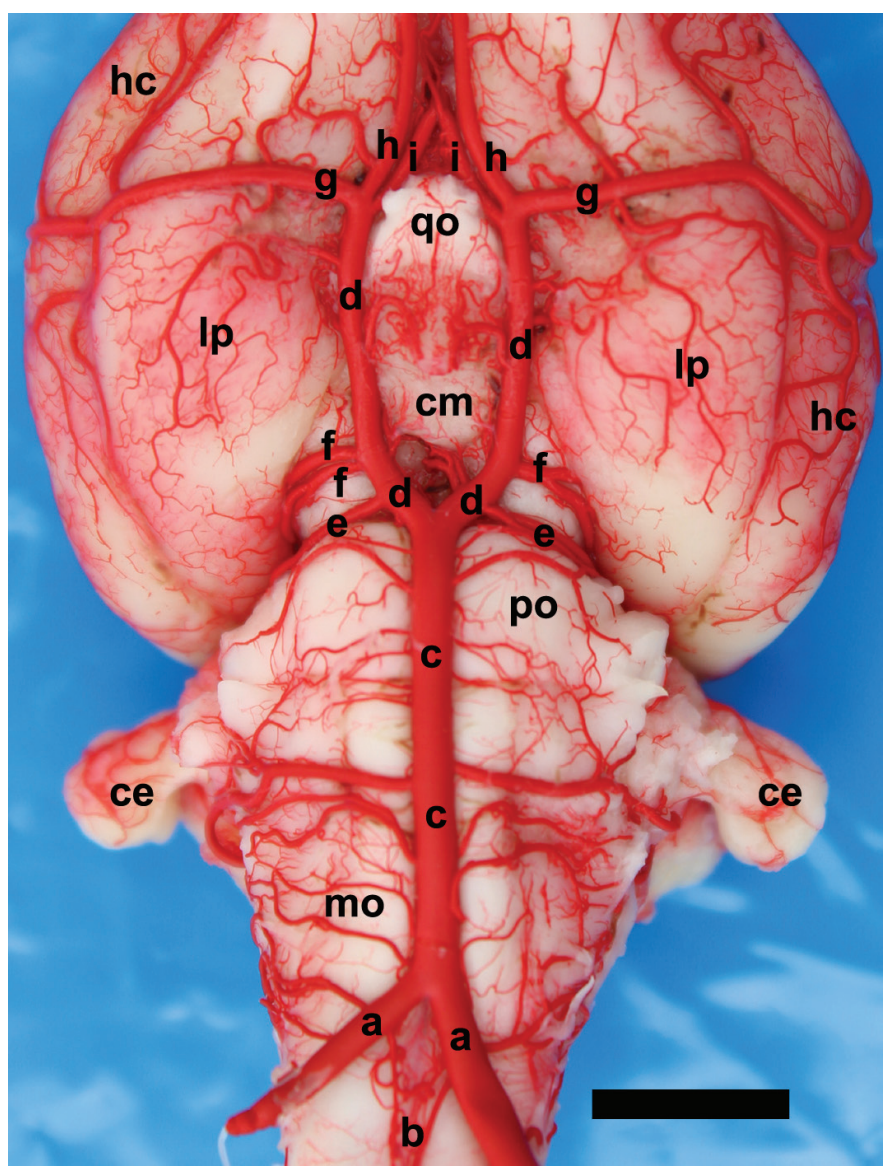

Fig.1. Ventral view of the nutria (Myocastor coypus) brain (Obs.18), highlighting the formation of the cerebral arterial circle and the cerebral arteries. Vertebral artery(a), ventral spine artery (b), basilar artery (c), terminal branch of "c" (d), cerebellar rostral artery (e), caudal cerebral artery (f), middle cerebral artery (g), cerebral rostral artery (h), medial branch of " $h$ " (i), cerebral hemisphere (hc), optical chiasm (qo), nipple body (cm), piriform lobe (lp), bridge (po), cerebellum (ce), medulla oblongata (mo). Bar $=7 \mathrm{~mm}$. 
artery in $33.3 \%$ and $23.3 \%$ of the cases to right and the left, respectively. The rostral tectal mesencephalic artery, a distal component in both antimeres, was observed as a double vessel in all preparations.

The caudal inter-hemispheric artery was the continuation of the main axis of the caudal cerebral artery, which, when penetrating the transverse fissure of the brain, emitted a sequence of two to three central branches to the paleopallial of the piriform lobe (caudomedial part). It also emitted largecaliber caudal choroidal branches to the diencephalon and two rostral tectal mesencephalic branches, distal components, to the network of the mesencephalic tectum. The caudal interhemispheric artery was presented as a single vessel in $100 \%$ of the samples in both antimeres.

Near the rostral colliculi, the caudal inter-hemispheric artery curved dorsally, projecting two to three occipital hemispheric arteries. Its terminal branch was a thin-caliber vessel that anastomosed "in osculum" with the terminal branch of the rostral inter-hemispheric artery, the terminal branch of the rostral cerebral artery, at the level of the splenium of the corpus callosum.

The central branches of the caudal inter-hemispheric artery to the right varied from two to three branches in $83.3 \%$ of the samples and from one to six branches in $16.7 \%$ of them, whereas to the left, they varied from two to three branches in $86.7 \%$ of the preparations and from one to four branches in $13.3 \%$ of them.

The caudal inter-hemispheric artery, when passing over the medial geniculate body, emitted caudal choroidal branches that projected medial-rostrally on the thalamic mass, vascularizing the diencephalic structures and the hippocampus. It anastomosed with the rostral choroidal artery, vascularize the diencephalic structures (lateral geniculate body, thalamic mass, medullary streak, pineal gland and third ventricle
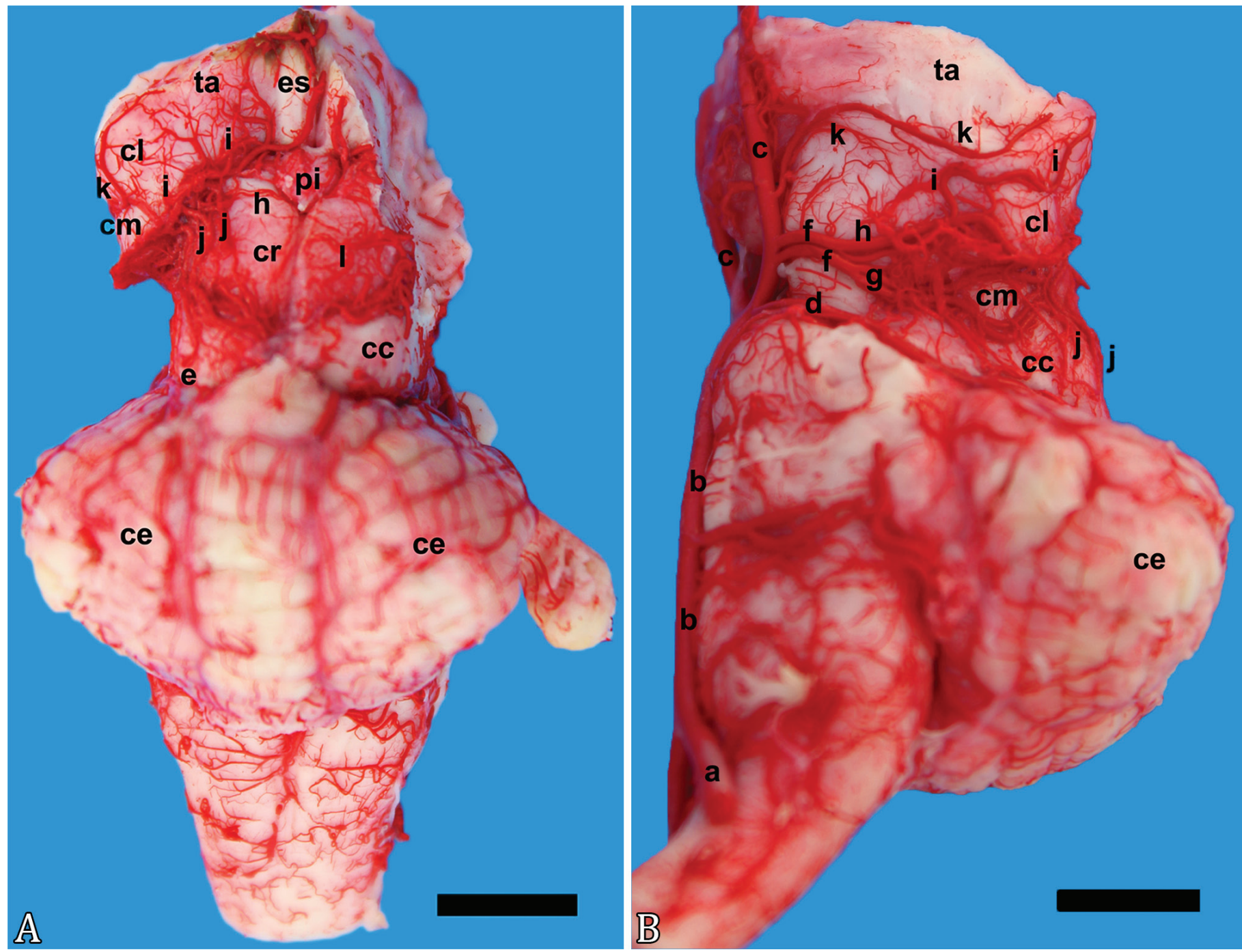

Fig.2. (A) Dorsal and (B) left lateral views of the brainstem, with cerebellum, of nutria (Myocastor coypus) (Obs.14). Vertebral artery (a), basilar artery (b), terminal branch of "b" (c), cerebellar rostral artery (d), caudal tectal mesencephalic artery (e), caudal cerebral artery (f), rostral tectal mesencephalic artery - proximal component (g), caudal inter-hemispheric artery (h), caudal choroid artery (i), rostral tectal mesencephalic artery - distal component (j), rostral choroid artery (k), network of the mesencephalic tectum(l), medullar streaks (es), thalamus (ta), lateral geniculate body (cl), medial geniculate body (cm), rostral colliculi (cr), caudal colliculi (cc), pineal gland (pi), cerebellum (ce). (A) Bar $=6.1 \mathrm{~mm}$. (B) Bar $=5 \mathrm{~mm}$. 
choroid plexus) and the hippocampus. Most caudal branches of the caudal choroidal artery protruded over most part of the rostral colliculi, anastomosing with the network of the

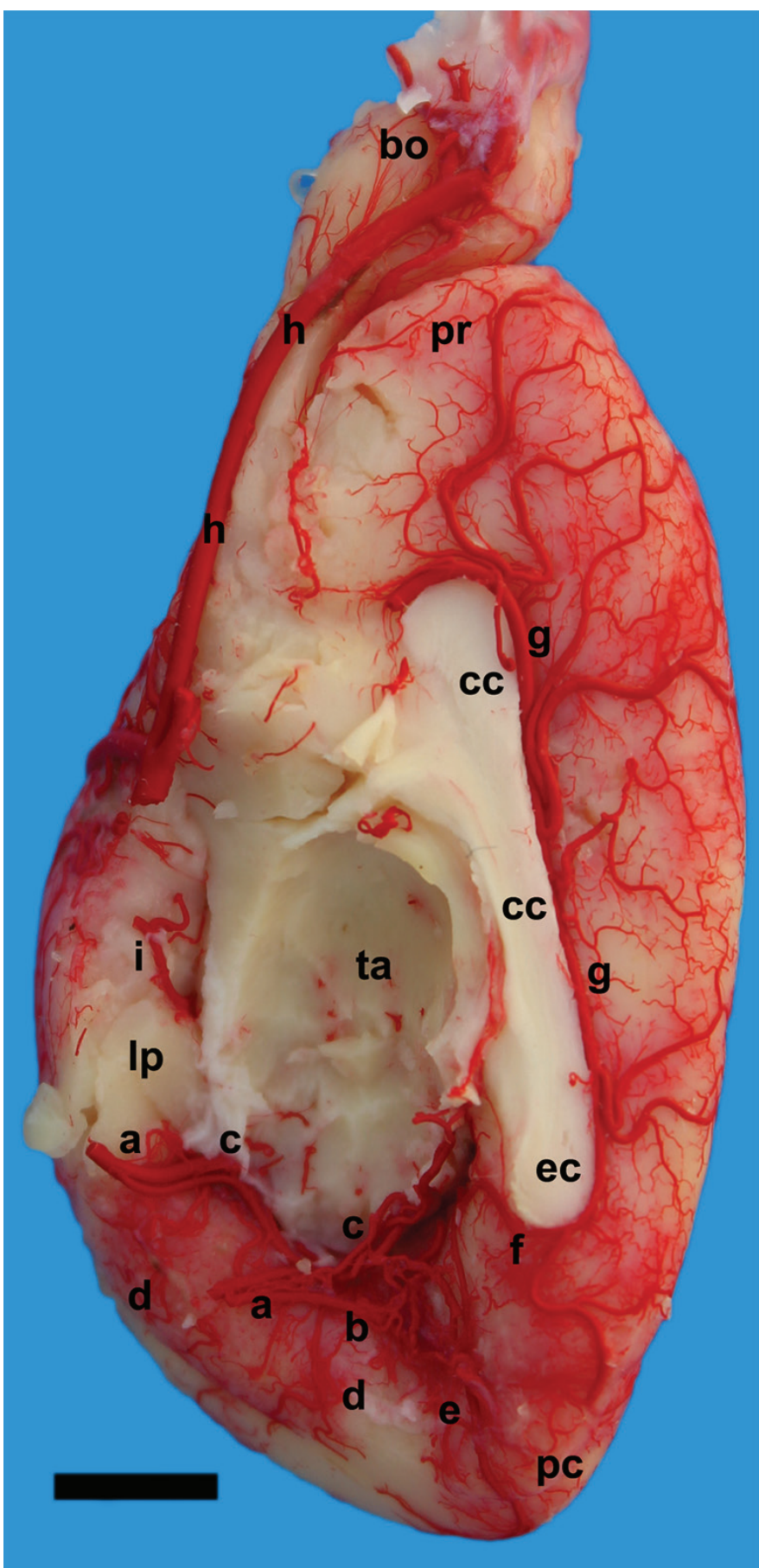

Fig.3. Right medial view of the cerebral hemisphere in nutria (Myocastor coypus) (Obs.18). Caudal cerebral artery (a), rostral tectal mesencephalic artery - proximal component (b), caudal inter-hemispheric artery (c), central branch of "a" (d), occipital hemispheric branch (e), anastomosis between interhemispheric rostral and caudal arteries (f), inter-hemispheric rostral artery (g) main axis of cerebral rostral artery (h), rostral choroid artery (i), olfactory bulb (bo), rostral pole of the cerebral hemisphere (pr), caudal pole of the cerebral hemisphere (pc), corpus callosum (cc), splenium of "cc" (ec), thalamus (ta), piriform lobe (lp). Bar $=4.5 \mathrm{~mm}$. rostral tectal mesencephalic arteries. The caudal choroidal artery was a single vessel in both antimeres in all samples.

The caudal inter-hemispheric artery, when reaching the cerebral hemisphere, originated from one to three occipital hemispheric branches. These thin-caliber vessels, were emitted, in sequence, to the occipital pole of the cerebral hemisphere, reaching the convex surface. The progress of these ramifications was very small on this side. Its terminal branches anastomosed with the caudal convex hemispheric terminal branches of the middle cerebral artery.

The hemispherical occipital branches in $70 \%$ on the right and $43.3 \%$ on the left, were double; in $16.7 \%$ on the right and in $36.7 \%$ on the left, it was triple; in $13.3 \%$ on the right and in $20 \%$ on the left, it was shown as a single vessel (Fig.4).

The territory of the caudal cerebral artery in nutria comprised a small caudal and medial area of the piriform lobe, the tentorial surface of the cerebral hemisphere, a small caudal area of the convex surface, limiting the transverse fissure of the brain, the mesencephalic tectum, except the caudal face of the caudal colliculi, the pineal gland, the medullary streaks, the habenula, the lateral and medial geniculate body, the thalamic mass, and the third ventricle choroid plexus. It also comprised the splenium of the corpus callosum, the fornix, and the hippocampus. The structures of the diencephalic tectum presented vascular complementation by the rostral choroidal artery, which was a collateral branch of the terminal branch of the basilar artery (Fig.5).

Distribution of the caudal cerebral artery and its branches showed anastomoses with the terminal branches of the middle cerebral artery at the caudal limit of the convex surface of the cerebral hemisphere. They also presented anastomosis with the caudal tectal mesencephalic artery, a branch of the rostral cerebellar artery, at the limit of the caudal and rostral surfaces of the caudal colliculi.

\section{DISCUSSION}

The caudal cerebral artery in nutria (Myocastor coypus) was normally single, medium-caliber vessel originated from the terminal branches of the basilar artery at the base of the cerebral peduncle close to the oculomotor nerve (III pair of cranial nerve). This description was also found in studies on capybaras (Hydrochoerus hydrochaeris) (Reckziegel et al. 2004a), chinchillas (Chinchilla lanigera) (Araújo \& Campos 2007), and nutrias (Goltz 2017, Azambuja et al. 2018). In rats (Mus rattus), the caudal cerebral artery originated from the initial portion of the rostral cerebellar artery, which emitted branches to the thalamus region (Scremin 1995). In rats (Rattus norvegicus) and gerbil (Meriones unguiculatus), the caudal cerebral artery was emitted from the terminal branch of the internal carotid artery, as a single, large-caliber vessel (Kuchinka et al. 2008, Esteves et al. 2013). In Cairo spiny mouse (Acomys cahirinus, Desmarest), the arteries at the base of the brain showed a wide range of presentations, such as open, partially open and closed arterial circles, with the caudal cerebral artery originating from the internal carotid artery in some cases, and in the basilar artery in others (Szczurkowski et al. 2007).

In nutria, the right caudal cerebral artery was presented as single in $66.7 \%$ of the preparations and double in $33.3 \%$ of them, whereas to the left it was presented as single in $76.7 \%$ of the samples and double in $23.2 \%$ of them. Unlike 
in nutria, the caudal cerebral artery in capybara was mainly single, both to the right and the left, with cases of triplicity. Emergence in the right antimere was double in 56.7\%, simple in $40 \%$ and triple in $3.3 \%$ of the samples, whereas to the left antimere it was single in 53.3\%, double in $40 \%$ and triple in $6.7 \%$ of them (Reckziegel et al. 2001). The caudal cerebral artery in nutria was also a single vessel in $66.7 \%$ of the cases to the right, but was single in $73.3 \%$ of the case to the left (Goltz 2017, Azambuja et al. 2018). In chinchilla, the caudal cerebral artery was a single vessel in $53.3 \%$ of the samples to the right and in $63.3 \%$ of them to the left however, it was double in $46.7 \%$ to the right and $36.7 \%$ to the left, where most of the rostral artery showed large caliber and the flow rate was from the caudal choroidal artery (Araújo \& Campos 2007). In chinchilla, the main caudal component was the caudal choroidal artery, whereas in nutria it was the rostral tectal mesencephalic artery. In chinchilla, the rostral tectal mesencephalic artery was always a direct branch of the terminal branch of the basilar artery, not being dependent on the caudal cerebral artery as in nutria. In $R$. norvegicus, the caudal cerebral artery was a single vessel, and duplication often occurred (Esteves et al. 2013).

In nutria, the caudal cerebral artery emerged as collateral branches of the rostral tectal mesencephalic artery (proximal component) and the caudal inter-hemispheric artery. The same description was found in nutria (Goltz 2017, Azambuja et al. 2018). The caudal cerebral artery in Guinea pig originated in the collateral branches that went to the occipital, lateral temporal and parietal areas of the cerebral hemispheres (Majewska-Michalska 1995). In capybara, on the dorsal surface of the cerebral hemisphere, the caudal cerebral artery ran to the para-hippocampal gyrus, emitting small branches, which penetrated the hippocampal groove, and small branches, which were superficially distributed along the hippocampal formation (Reckziegel et al. 2004b). In nutria, the hippocampus was vascularized by the rostral and caudal choroidal arteries, with the caudal choroidal artery being a branch of the caudal inter-hemispheric artery. In M. rattus, the caudal cerebral artery joined the caudal communicating artery and formed the caudal mesencephalic tectal artery, whose branches irrigated the surface of the caudal colliculi.
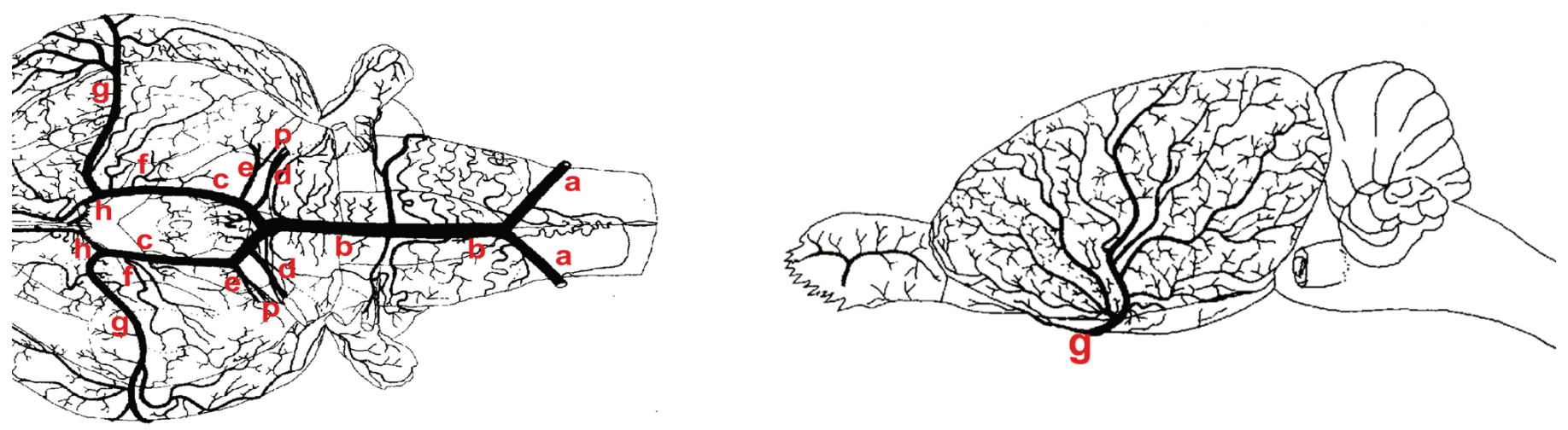

令

这

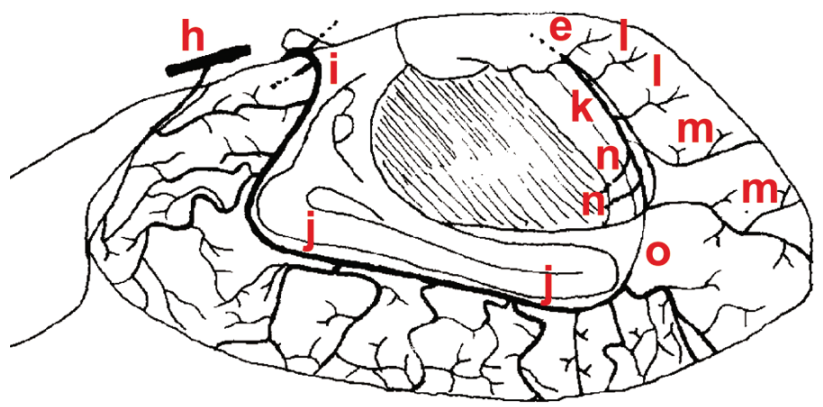

G

D)

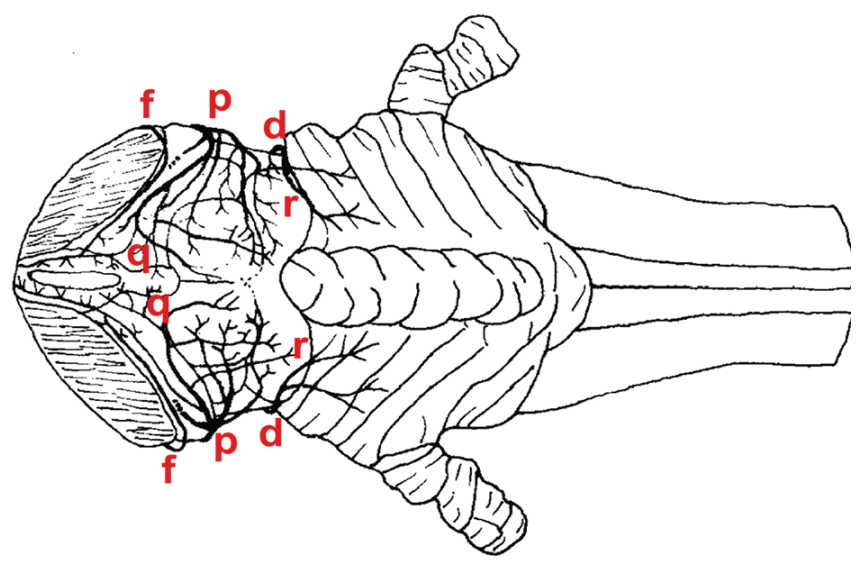

Fig.4. Schematic drawings in (A) ventral, (B) left lateral, (C) left medial and (D) dorsal views of brainstem with cerebellum in nutria (Myocastor coypus) (Obs.3). Vertebral artery (a), basilar artery (b), terminal branch of "b" (c), cerebellar rostral artery (d), caudal cerebral artery (e), rostral choroid artery (f), middle cerebral artery (g), cerebral rostral artery (h), medial branch of " $h$ " (i), inter-hemispheric rostral artery (j), caudal inter-hemispheric artery (k), central branches of "e" (l), occipital hemispheric branches (m), rostral tectal mesencephalic artery - distal component (n), anastomosis between interhemispheric rostral and caudal artery (o), rostral tectal mesencephalic tectal artery - proximal component (p), caudal choroid artery (q), caudal tectal mesencephalic artery (r). 
Then it emitted the longitudinal hippocampal artery, the caudal lateral choroidal artery (for the lateral ventricle and the third ventricle choroid plexus) and three to four cortical branches. The caudal cerebral artery ended in a collateral anastomotic network on the surface of the rostral and caudal colliculi (Scremin 1995).

The rostral tectal mesencephalic artery in M. coypus originated from the caudal cerebral artery, dorsally. In the samples where the caudal cerebral artery was a double vessel, the first component that emerged from the terminal branch of the basilar artery was the rostral tectal mesencephalic artery, its proximal component. When the caudal cerebral artery appeared as a single vessel, the rostral tectal mesencephalic artery was its first collateral branch. The rostral tectal mesencephalic artery vascularized most of the mesencephalic tectum, except the caudal surface of the caudal colliculi, which was vascularized by the caudal tectal mesencephalic artery, a branch of the rostral cerebellar artery. The same description was found in nutria (Goltz 2017, Azambuja et al. 2018). In capybara, the rostral tectal artery was distributed in the mesencephalic tectum, in the rostral colliculi, and part of the caudal colliculi, further vascularizing the para-hippocampal gyrus, the hippocampus, and the thalamus (Reckziegel et al. 2004a). In chinchilla this artery was emitted from the terminal branch of the basilar artery, between the origins of the rostral cerebellar and caudal cerebral arteries (Araújo \& Campos 2007).

In nutria, the terminal branches of the rostral and caudal mesencephalic tissue arteries formed a typical anastomotic network on the surface of the rostral and caudal colliculi. In the rostral tectal mesencephalic arteries, the distal components were emitted from the inter-hemispheric artery and the caudal choroidal artery. Unlike in nutria, in capybaras, the rostral tectal artery emerged as a collateral branch of the caudal cerebral artery in $27.9 \%$ of the samples and was emitted directly from the basilar artery in $72.1 \%$ of them (Reckziegel et al. 2004a). In chinchilla, the rostral tectal artery was a single vessel in $96.7 \%$ of the samples on the right and in $90 \%$ of them to the left. However, two rostral tectal arteries were emitted from the terminal branch of the basilar artery in $3.3 \%$ of the samples to the right and $10 \%$ to the left (Araújo \& Campos 2007).

The next branch of the caudal cerebral artery in nutria was the caudal inter-hemispheric artery. The latter projected two to three central branches to the medial surface of the piriform lobe the caudal part. The caudal inter-hemispheric artery was single in $100 \%$ of the encephalo both to the right and left. The chinchilla caudal inter-hemispheric artery was the continuation of the caudal cerebral artery, after the emission of the first caudal hemispheric branch to the tentorial part of the medial surface of the cerebral hemisphere, and ascended branching on the medial surface of the cerebral hemisphere,

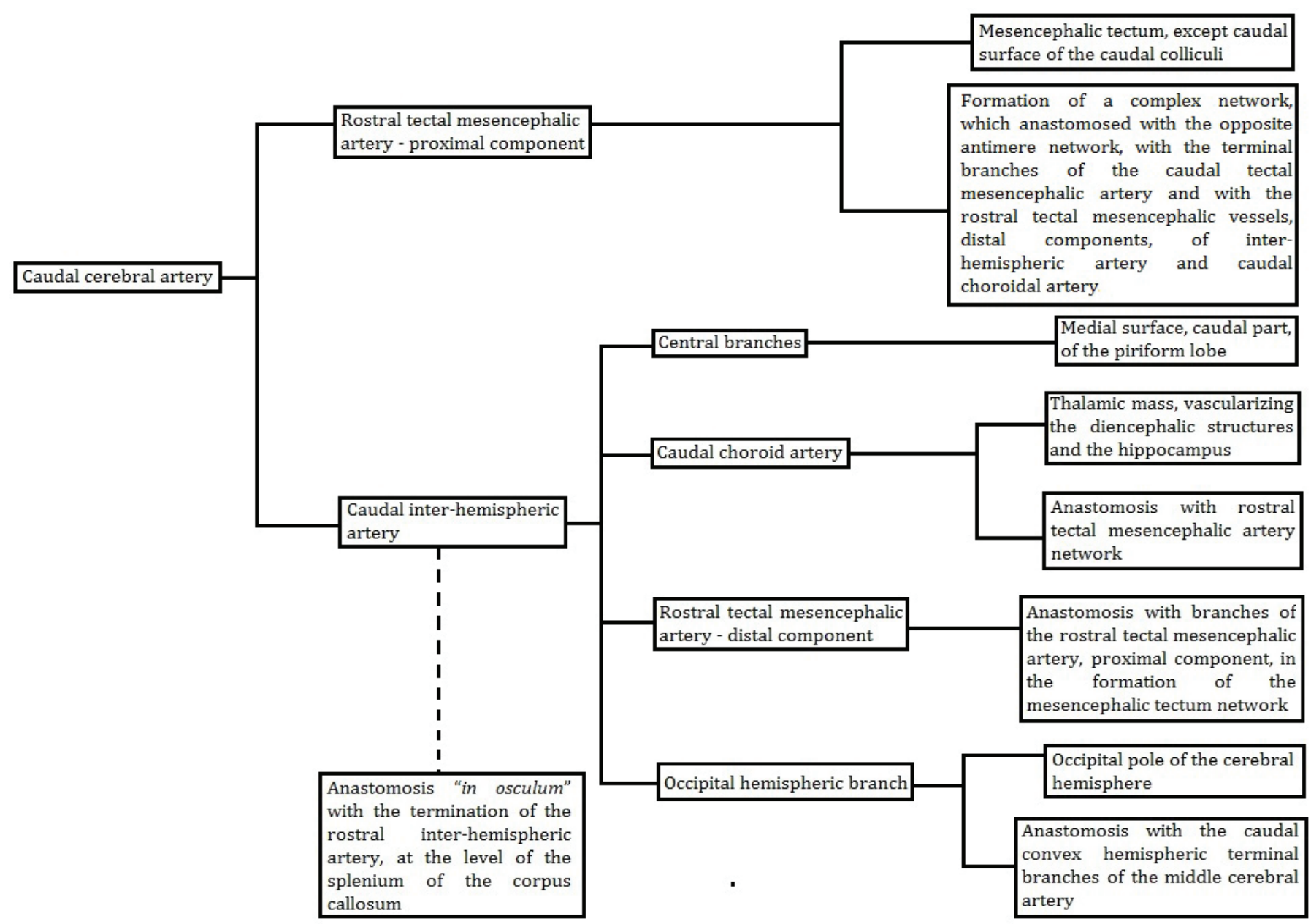

Fig.5. Organization chart showing the cerebral caudal artery in nutria (Myocastor coypus) and its distribution. 
emitting the para-hippocampal gyrus and caudal medial hemispheric branches (Araújo \& Campos 2007). In chinchilla, when the caudal cerebral artery ascended, thin-caliber central branches were emitted on the lateral surface of the cerebral peduncle, being distributed ventrally, in most of the caudal third of the piriform lobe. On the right, two central branches were emitted in $53.3 \%$ of the samples, three branches in $20 \%$, four branches in $16.7 \%$ and one branch in $10 \%$; on the left, they projected three branches in $40 \%$, two branches in $26.7 \%$, one branch in $20 \%$ and four branches in $13.3 \%$ of the preparations (Araújo \& Campos 2007).

The caudal inter-hemispheric artery in nutria emitted a well-developed caudal choroidal artery, which before bypassing the lateral geniculate body anastomosed with the rostral choroidal artery, where both branched out on the thalamic mass, vascularizing all the structures of the diencephalon and hippocampus. The caudal choroidal artery, in capybara, arose from the caudal cerebral artery rostral-medially on the hippocampal gyrus, and it anastomosed with the rostral choroidal artery (Reckziegel et al. 2004b). The chinchilla caudal choroidal artery was a single or double thin-caliber vessel. It was projected dorsal-medially vascularizing the hippocampus, ventrally following the fimbria, reaching and running through the terminal medullar streak, emitting branches to the third ventricle choroid plexus and the lateral ventricle (Araújo \& Campos 2007).

The caudal choroidal artery in capybara was presented anastomosed with the rostral choroidal artery, contributing to the formation of the third ventricle choroid plexus and the lateral ventricle (Reckziegel et al. 2004a). In chinchilla, the caudal choroidal artery, when double, had one component originating from the caudal cerebral artery and the other originating from the terminal branch of the basilar artery in $46.6 \%$ of the cases to the right and $36.7 \%$ on the left, and it was also double, being the only branch of the caudal cerebral artery in $26.7 \%$ of the samples to the right and in $33.3 \%$ of them to the left, and it was a single vessel, branch of the caudal cerebral artery in $26.7 \%$ to the right and $30 \%$ to the left (Araújo \& Campos 2007).

The caudal inter-hemispheric artery in M. coypus emitted, near the medial geniculate body, the rostral mesencephalic tectal artery, a distal component, a double vessel, which anastomosed to the branches of the rostral tectal mesencephalic artery, proximal component, participating in the formation of the network of the mesencephalic tectum. This distal component has never been mentioned in any other animal species. Then the caudal inter-hemispheric artery emitted, to the medial surface (tentorial part) of the cerebral hemisphere, occipital hemispheric arteries, which were thin-caliber vessels that reached the occipital (caudal) pole of the cerebral hemisphere. The caudal inter-hemispheric artery in chinchillas emitted caudal-medial, collateral hemispheric branches to the tentorial and medial portion of the cerebral hemisphere surface. Two to seven caudal-medial, collateral hemispheric branches originated from the right and left (Araújo \& Campos 2007).

In nutria, the caudal inter-hemispheric artery became a thin-caliber vessel that, bypassing the splenium of the corpus callosum, anastomosed "in osculum" with the termination of the rostral inter-hemispheric artery. The same description was found in chinchilla, and this anastomotic branch was present in $88.3 \%$ of the samples to the right and $76.7 \%$ of them to the left (Araújo \& Campos 2007). In capybara, the terminal branch of the caudal cerebral artery emitted, on the medial side of the cerebral hemispheres, a rostral anastomotic branch to the corpus callosum artery, which is the terminal branch of the rostral cerebral artery (Reckziegel et al. 2004a).

It was concluded that the vascular territory of the caudal cerebral artery in capybara (Reckziegel et al. 2004a) included the thalamus, the rostral colliculi, part of the caudal colliculi, the caudal surface of the piriform lobe, the tentorial surface, the rostral splenium portion of the medial surface, and convex surface of the cerebral hemispheres along the longitudinal and transverse fissures of the brain. Arterial vascularization of the hippocampus in capybara (Reckziegel et al. 2004b) was supplied by branches originating from the caudal cerebral artery and the rostral choroidal artery. The territory of the caudal cerebral artery in chinchilla comprised the caudal third of the piriform lobe, the pineal gland, the medullary streak, the habenula, the dorsal surface of the thalamus, the lateral and medial geniculate bodies, the hippocampus, the third ventricle choroid plexuses and the lateral ventricle, the splenic corpus callosum, the tentorial part of the medial surface of the cerebral hemisphere, and the caudal part of the convex surface, bypassing the transverse fissure of the brain (Araújo \& Campos 2007). The basic difference in the territorial area of the caudal cerebral artery between nutria and chinchilla was that the rostral colliculi was vascularized by the rostral tectal mesencephalic artery, and did not belong to the vascularization of the caudal cerebral artery, but was a branch of the terminal branch of the basilar artery.

In nutria, the distribution of the caudal cerebral artery and its branches showed anastomoses with the terminal branches of the middle cerebral artery at the caudal limit of the convex surface of the cerebral hemisphere. In nutria (Goltz 2017, Azambuja et al. 2018) and in chinchilla (Araújo \& Campos 2007), it has been described that the terminal branches of the caudal cerebral artery anastomoses "in osculum" with the terminations of the rostral cerebral artery close to the splenium of the corpus callosum. In chinchilla (Araújo \& Campos 2007), anastomoses were also observed between the terminal branches of the caudal cerebral artery and the terminal branches of the middle cerebral artery, on the convex surface of the cerebral hemisphere, surrounding the entire transverse fissure of the brain and the caudal third of the piriform lobe. In G. pig, in the diencephalon, the thalamus received branches from the caudal cerebral, the caudal communicating, and the rostral and middle cerebral choroid artery (Majewska-Michalska 1995, 1997). The caudal cerebral artery in capybara (Reckziegel et al. 2004a) projected to the caudal part of the piriform lobe, the para-hippocampal gyrus, and the caudoventral portion of the cerebral hemispheres and emitted cortical branches to the caudal surface of the piriform lobe and tentorial surface of the cerebral hemisphere, where it anastomosed with cortical branches of the middle cerebral artery. In the caudal region of the brain of $M$. rattus, anastomoses were observed between the azygos pericallosal artery and middle cerebral and caudal cerebral arteries (Scremin 1995).

\section{CONCLUSIONS}

The caudal cerebral artery in nutria is a branch of the terminal branch of the basilar artery whose ramifications are distributed with greater emphasis on the mesencephalic tectum 
and the diencephalon, vascularizing the entire hippocampus, but extending very little onto the neopallium of the caudal pole and the medial surface of the cerebral hemisphere.

The caudal cerebral artery and its terminal branches present anastomosis with the terminal branches of the rostral and middle cerebral arteries in a restricted region of the caudal pole of the cerebral hemisphere.

In nutria, the vascularization area of the caudal cerebral artery and its central branches in the paleopallial of the piriform lobe is extremely restricted caudal-medially to it.

Acknowledgements.- The authors would like to thank "Coordenação de Aperfeiçoamento de Pessoal de Nível Superior" (CAPES) for the scholarship provided.

Conflict of interest statement.- The authors report no conflicts of interest and are responsible for the contents of this manuscript.

\section{REFERENCES}

Alcântara M.A. 1992. Estudo anatômico das artérias da base do encéfalo de cães (Canis familiaris Llnnaeus, 1758). Master's Thesis, Faculdade de Medicina Veterinária e Zootecnia, Universidade de São Paulo, São Paulo, SP. 134p.

Araújo A.C.P. \& Campos R. 2005. A systematic study of the brain base arteries and their blood supply sources in the chinchilla (Chinchilla lanigera Molina, 1782). Braz. J. Morphol. Sci. 22(4):221-232.

Araújo A.C.P. \& Campos R. 2007. Systematization, distribution and territory of the caudal cerebral artery on the surface of the brain in chinchilla (Chinchilla lanígera). Braz. J. Morphol. Sci. 24(3):180-186.

Araújo A.C.P., Oliveira J.C.D. \& Campos R. 2004. Ramos colaterais do arco aórtico e suas principais ramificações em chinchila (Chinchilla lanigera). Revta Port. Ciênc. Vet. 99(549):53-58.

Azambuja R., Goltz L.V. \& Campos R. 2018. Sistematização das artérias da base do encéfalo em nutria (Myocastor coypus). Acta Scient. Vet. 46:1580. <http://dx.doi.org/10.22456/1679-9216.85811>

Baroffio R., De Paoli J. \& Fiordelisi A. 1979. Clasificacion zoológica de la nutria, p.2-5. In: Baroffio R., De Paoli J. \& Fiordelisi A. (Eds), Nuestra Nutria (Myocastor coypus). Hemisferio Sur, Buenos Aires.

Bugge J. 1971. The cephalic arterial system in New and Old World hystricomorphs, and bathyergoids, with special reference to the systematic classification of rodents. Acta Anat. 80(4):516-536. <http://dx.doi.org/10.1159/000143713> <PMid:5137926>

Bugge J. 1974. The cephalic arterial system in insectivores, primates, rodents and lagomorphs, with special reference to the systematic classification. Acta Anat. 62:1-159. <PMid:4207099>

Campos R. 1987. Contribuição ao estudo das artérias carótidas na base do encéfalo em Gallus gallus. Master's Thesis, Faculdade de Medicina Veterinária e Zootecnia, Universidade de São Paulo, São Paulo, SP. 101p.

De Vriese B. 1905. Sur la signification morphologique des artères cérébrales. Arch. Biol. 21:357-457.

Depedrini J.S. \& Campos R. 2003. A systematic study of the brain base arteries in the pampas fox (Dusicyon gymnocercus). Braz. J. Morphol. Sci. 20(3):181-188.

Esteves A., Freitas A.C., Rossi-Junior W.C. \& Fernandes G.J.M. 2013. Anatomical arrangement and distribution of the cerebral arterial circle in rats. J. Morphol. Sci. 30(2):132-139.
Ferreira C.G. 1998. Estudo anatômico das artérias da base do encéfalo de suínos (Sus scrofa domesticus Linnaeus, 1758). Master's Thesis, Faculdade de Medicina Veterinária e Zootecnia, Universidade de São Paulo, São Paulo, SP. 98p.

Gielecki J.S., Brudnicki W. \& Nowaki M.R. 1996. Digital-image analysis of the brain-base arteries in chinchilla, Chinchilla laniger (Molina). Anat. Histol. Embryol. 25(2):117-119. <http://dx.doi.org/10.1111/j.1439-0264.1996. tb00068.x>

Goltz L.V. 2017. Sistematização, distribuição e territórios das artérias cerebrais rostral, média e caudal na superfície do encéfalo em nutria (Myocastor coypus). Master's Thesis, Faculdade de veterinária, Universidade Federal do Rio Grande do Sul, Porto Alegre, RS. 173p.

Jablonski R. \& Brudnicki W. 1984. The effect of blood distribution to the brain on the structure and variability of the cerebral arterial circle in musk-rat and in chinchilla. Folia Morphol. 43(2):109-114. <PMid:6335451>

Kuchinka J., Nowak E., Szczurkowski A. \& Kuder T. 2008. Arteries supplying the base of the brain in the Mongolian gerbil (Meriones unguiculatus). Pol. J. Vet. Sci. 11(4):295-299. <PMid:19227126>

Lazorthes G., Gouazé A. \& Salamon G. 1976. Anatomie comparée du système artéril de l'encéphale, p.14-30. In: Lazorthes G., Gouazé A. \& Salamon G. (Eds), Vascularization et Circulation de L'encéphale. Masson, Paris.

Lindemann T. 1994. Sistematização das artérias na base do encéfalo em Didelphis albiventris (gambá). Master's Thesis, Graduate Course in Vaterinary Science, Universidade Federal do Rio Grande do Sul, Porto Alegre, RS. 134p.

Majewska-Michalska E. 1995. Vascularization of the brain in Guinea pig II. Regions of vascular supply and spatial topography of the arteries in particular parts of the brain. Folia Morphol. 54(1):33-40.<PMid:8537066>

Majewska-Michalska E. 1997. Vascularization of the brain in Guinea pig V. Angioarchitectonics of the thalamus, telencephalon and internal capsule. Folia Morphol. 56(1):55-62. <PMid:9409080>

Nomina Anatomica Veterinaria 2017. Nomina Anatomica Veterinaria. International Committee On Veterinary Gross Anatomical Nomenclature. 6th ed. Hannover, p.73-147.

Oliveira J.C.D. 2004. Sistematização das artérias da base do encéfalo, rede admirável epidural rostral e caudal e suas fontes de suprimento em javali (Sus scrofa scrofa). Doctoral Dissertation, Graduate Course in Veterinary Science, Universidade Federal do Rio Grande do Sul, Porto Alegre, RS. 184p.

Reckziegel S.H., Lindemann T. \& Campos R. 2001. A systematic study of the brain base arteries in capybara (Hydrochoerus hydrochaeris). Braz. J. Morphol. Sci. 18(2):103-110.

Reckziegel S.H., Schneider F.L., Edelweiss M.I.A., Lindemann T. \& Culau P.O.V. 2004a. Anatomy of the caudal cerebral artery on the surface of the capybara (Hydrochoerus hydrochaeris). Braz. J. Morphol. Sci. 21(3):131-134.

Reckziegel S.H., Schneider F.L., Edelweiss M.I.A., Lindemann T. \& Culau P.O.V. 2004b. Vascularização arterial do hipocampo em Hydrochoerus hydrochaeris (capivara). Revta Port. Ciênc. Vet. 99(551):145-148.

Roskosz T., Jablonski R. \& Wiland C. 1988. The arteries of the brain base in chinchilla, Chinchilla laniger (Molina). Ann. Warsaw Agricult. Univ. 14:23-28.

Scremin O.U. 1995. Cerebral vascular system, p.3-18. In: Scremin O.U. (Ed.), The Rat Nervous System. 2nd ed. Sydney Academy Press, Sydney.

Szczurkowski A., Kuchinka J., Nowak E. \& Kuder T. 2007. Topography of arterial circle of the brain in Egyptian spiny mouse (Acomys cahirinus, Desmarest). Anat. Histol. Embryol.36(2):147-150.<http://dx.doi.org/10.1111/j.1439-0264.2006.00747.x> $<$ PMid:17371389>

Tandler J. 1898. Zur vergleichenden anatomie der Kopfarterien bein den Mammalia. Denkschriften der Akademie der Wissenschaften 67:677-784. 